\title{
Essay:
}

\section{Questioning the Question: How can a husband rape his wife?}

A Discussion in an International Classroom

by

Anjali Nicole Walquist

November 2014 


\section{Introduction}

This essay discusses the question "How can a husband rape his wife?" I assume that upon reading this you already have some reaction or answer. I have one, too. The interesting part is that they can be very different. Some people think along the lines of "Yes, I can't imagine how a husband can rape his wife because that is so cruel." Other people may think something like "Yes, how is this even possible, that a husband having sex with his wife could be considered rape." These views are quite different, and it is this difference that interests me.

The question has prompted many personal reflections and stimulating discussions. What is the cause of this difference? What do you think about the viewpoint that is not your own? How should you discuss this issue? What resources can aid your discussion? How should it be handled between social work and service users? How will this affect social work as a profession?

The question of marital rape brings up some issues that are very important to modern social work, as the world and social work are constantly becoming more global in scope. This question seems to have a different meaning to people from different countries. Does that mean it is a question of culture? What does this mean for social work? Social work is an international profession and one in which context matters quite a bit. How will this issue affect social work? Fook describes a part of modern social work as questioning what you know, but also how you know it (2002). Keeping this idea in mind will not only help me understand my own view, but other people's views on this matter as well.

In this essay, I will reflect upon the question "How can a husband rape his wife?" I will discuss my personal background, and describe the situation and experience in which this question was brought up. Next, I will discuss various reflections I have had about this difference. I will then reflect on how this idea, or even the definitions of the terms, may be based on a person's culture, gender, and/or opinions. After that, I will look at how this topic may affect social workers, service users and social work as a profession. Lastly, I will also explain how this has helped me gain a better understanding of this issue. 


\section{My Background}

Position and background are important to this discussion, so I will begin by describing my own. I'm from the United States of America (US), and I am currently studying in a master's social work program at a university in northern Norway, which has students from many different countries. Due to my status as an international student, I feel that my position in a multicultural classroom is defined by my American nationality. I have found this to be a thought provoking experience because it is different than what I am used to.

Growing up, I never felt like a real American. My parents both immigrated to the US from Australia. My mother immigrated to Australia from India and my father's father immigrated to Australia from Slovenia, and looking any further back into my genealogy becomes too complicated. If a discussion opposing immigration in the US occurs, I feel obligated to say, "Hey, my parents are immigrants." In the US, you are often asked what race you are on various forms. The only box I fit in was "multiracial" or "other." If I was around people with a more obvious race than me I would be "white," but if I was around mostly white people I would be "ethnic." For example, in a traditional Indian outfit around other Indians, I feel "white," whereas in a traditional Indian outfit around Americans, I feel "ethnic." I have also noticed people's opinions of what culture I have adapted once they meet my family because both my parents have obvious foreign accents. Since I am also female, I fit quite well into the minority box in the US. I have received benefits by being a minority, such as scholarships and special placement opportunities, though I often feel uneasy when I get these benefits because I am not really sure how to define myself. I have also had jokes made about me being a minority, as well as not being enough of a minority. I have experienced Indian, Australian and American culture throughout my life. In the US, these differences are enough to make me not feel $100 \%$ American. If I had to pick one culture, I would be American, although sometimes this is quite limiting.

After starting this course in Norway, I felt like my personal position had changed. The course focused on context and comparing perspectives, and since I am from the US, this became my context and perspective. Compared to some other countries, the US has a majority view in this day and age. I found this switch from minority to majority 
difficult at first. Why was my country being picked on in class? Should I defend it, even though I totally agree with why it is being picked on? How come other countries are not being questioned? I think this happened because the US is a world power and part of the majority, so naturally people are more aware of it and able to criticize it. Sometimes, it feels like everyone else seems to know more about the US than I do, and I often feel uneasy being American in a global setting because of the position the US is in. It seems like I should not criticize countries in the minority, but everyone can criticize my country because it is in the majority. I had not experienced being part of a majority view before because I felt like a minority in the US. There were times where being a minority had negative connotations, although the society I grew up in pushed for minority rights, acceptance and empowerment. Being part of the "majority" feels different because I do not feel that people are rooting for my rights or empowerment. This background information is important to my essay because it will influence the different ways I will look at this topic.

\section{Narrative}

A group of master's students studying social work gathered in northern Norway. These students were originally from China, England, Ghana, India, Lithuania, Malawi, Nepal, Pakistan and the US, with many of the students having traveled quite a bit throughout their lives. With such a diverse group, it is easy to imagine that there would be many unique opinions, ideas, beliefs, customs, expectations and thoughts, as these often help provide a comparative perspective to discuss within the class.

On this particular day, the students visited the local women's crisis center. During the presentation about the examples of abuse, the social worker explained how many of the women at the crisis center were raped by their husbands. A student asked the social worker, "But how can a husband rape his wife?" To me, the answer to this question is so painfully clear and obvious: A husband can rape his wife because she can say no to sex. I assumed that the students did not think the same way I did. Perhaps, they thought that the husband has the right to have sex with his wife, so therefore it would not be rape. Part of me expected the social worker and students to debate which was the correct answer, but the social worker just brushed over the question. Maybe she thought it was not a question, but more a comment like, "But 
how could a husband rape his wife because that is so cruel." She may not have caught the question, but either way she did not really seem to have any reaction, which surprised me. If she did not say anything about this question, then should I? The social worker was in a more qualified position for this discussion, and I would have liked to know what her thoughts would be.

After the visit to the women's crisis center was over, the question was brought up again by a few students. This time, there was no mistaking the meaning of the question, "How can a husband rape his wife?" It was more like, "But how can a husband rape his wife because that is not possible, it would not be rape." Another student and I attempted to explain our similar view, namely that a husband can rape his wife, and we talked about how a husband does not have the right to have sex with his wife whenever he wants. We explained how consent is required of both parties involved every time they have sex, otherwise it is rape. I said, "You need to get consent every time you have sex with someone even if they are your wife," which made someone laugh. I thought this was an odd reaction and made me feel like this was not going to be a discussion. Hence, I am not sure how well our point of view was understood since this discussion was very short.

I know that this question of marital rape has different answers depending on the country you are in. But since we were all in Norway, I assumed that the Norwegian answer would be the accepted one. I felt that being in the majority position was a hindrance because it does not get as much attention or a chance to explain itself. Sometimes, discussions end up being focused on whoever is the minority with the most struggles. In a lot of cases this is very necessary, but I do think both sides should be looked at, and I think this issue was more important than just who is right and wrong in the majority or minority opinion. The issue of abuse has consequences for people everywhere, regardless of gender, marital status, relationship, or nationality.

\section{A Question of Culture}

My first thought was that this is a cultural difference, but then what exactly is culture? Almost everything you do can be considered culture. I wonder if it may not be a 
cultural issue because most of the students in this course have traveled a lot and experienced many different cultures. Wouldn't this put them in a similar position as myself? Do other people hold onto their cultural roots more than I do? Or is it easier for me because my culture is somewhat similar to Norway? How much of your own culture should you compromise?

If this issue is a cultural difference, do you need to change your cultural beliefs to be a social worker in a different country? In my opinion, living in another country means making some cultural compromises. For example, I do not smile at random people in Norway because this is not part of Norwegian culture. But to be honest, I miss this part of American culture. No matter how fake and insincere randomly smiling at people is, I am used to it and think it is much better than not smiling at people. People who live in cultures other than their own often have to make similar or larger compromises. I also think that a social worker would need to compromise his or her cultural values somewhat to fit a local context. For example, incidents of children being hit in Norway should be reported, whether or not your culture defines this as an issue that needs to be reported. In my opinion, the social worker's values in practice need to be aligned with the given social context, unless the social workers are trying to change the local values.

Calling this a cultural difference puts it in a certain box that is troublesome to discuss. Culture has a certain power: you cannot easily disagree with someone's culture. It also makes the issue difficult because you are not on equal ground during the discussion. On the issue of marital rape, from a cultural perspective, opinions may be divided into the western majority and the non-Western minority. I believe too much value would be put on this issue of majority and minority culture rather than the real issue at hand. Luckily, none of the discussions I have had about this issue have prompted any arguments. In my opinion, culture is often a hot button issue because criticisms of culture are often taken personally.

Lustig and Koester discuss many important factors of intercultural competence such as cultural identity, cultural patterns, cultural bias, intercultural communications, intercultural interactions and intercultural competence (2010). I have found their 
literature to be very useful when reflecting about what culture is, and yet I feel compelled to consider this topic as something other than culture. Lustig and Koester bring up many difficulties of discussing cultural issues such as personal bias, problems with generalization and complicating issues with cultural tones (2010). These issues can be difficult to overcome. Lustig and Koester also discuss many examples of cultural differences, ranging from being asked to show an ID to speaking British or American English (2010). I have found these examples to be different than the incident I am focusing on because they focus on the personal experience. I had a personal experience during this situation and that my interpretation of my experience is partly cultural. In other words, my personal thoughts on this issue may be more culturally rooted than the issue itself. Thus, the issue must have some cultural ties, but I do not think this is the only way to look at it.

\section{A Question of Gender}

While discussing this topic with a teacher and fellow classmates, the question of gender was raised. I had not originally considered whether or not it was a gendered issue, but could it be? I could use feminist theories as presented by Connell to explain how the idea that a wife cannot be raped is oppressive and rooted in men setting social standards and dominating legal avenues (2013). I do think this helps me understand where the idea comes from, but I do not think there is single idea that explains this particular situation.

This situation took place with male students, who thought a husband could not rape his wife, and female students, who thought that a woman could be raped by her husband. This was just a matter of circumstance because the opinions of my other classmates were not divided by gender. Some of the female students thought a husband could not rape his wife, while some of the male students thought that a husband could rape his wife. I also asked whether a woman could rape her husband. Some students said women could rape their husband, though others said that men could not be raped. Many of my classmates thought that neither a man or a woman could suffer from marital rape. 
This leads me to believe it is not just an issue of gender, but also one of marital rights. Connell discusses how globalization has spread gender relations, gender inequalities and the interest of women (2013). Globalization has spread the idea that women have the right to consent in a marital relationship, but I maintain that cultural beliefs and customs influence the idea of what marriage is. This could be an issue of gender because some people may think men have a right to their wife, and that men cannot ever be raped. It could also be a gendered issue because in many cases men have decided what constitutes rape. For me, this viewpoint is more complicated than just being a gendered view, but does involve gendered issues.

\section{A Question of Opinion}

Is this just a difference of opinion? Since my precious reflections about culture and gender have shown that there is more to the situation, this may be an issue of opinion. Opinions encompass all of these things into an idea, though opinions can change, just like some students changed their views about this situation. Opinions are influenced by facts, beliefs, culture, gender and many other things, which seem similar to what my previous reflections have discovered about this topic. The inclusion of facts here is also important because opinions may be changed by new knowledge or education. Opinions can be compared with other opinions, as a discussion of opinions puts everyone on equal ground. In Norway, everyone can have an opinion and is allowed to discuss them openly.

What does it mean if this issue is a difference of opinion? Is opinion based on knowledge, education, or experience with a certain topic? I would argue that it must partially be based on these things. My opinions have changed after gaining new knowledge, receiving further education, or having new experiences. Do opinions involve ethics? I believe they do when needed to. Sharing opinions is a good way to discover and understand other people's ideas, as someone may have an opinion based on first-hand experience or extensive research. Knowing the basis for an opinion would help another person understand that person's opinion better.

Part of an opinion, of course, is that everyone can have one. Opinions are not limited to a certain culture, gender, or belief system. You can have opinions on almost 
anything and everything. Opinions can be discussed, shared and developed. You may not have an opinion on a certain issue to begin with, but you can explore the issue and create your own opinion. I think this is the best way of looking at this focus topic.

\section{A Question of Definitions}

Definitions may also play a large part in this discussion, which can vary a little or a lot. There can be different definitions of "rape." To me, it means having sex without consent, regardless of gender or previous relationships. This goes along with the definition in Norwegian law, as well as international human rights laws. The United Nations (UN) says that every person has individual rights, freedoms and the right not to be harmed (1948), though some countries do not have laws that define marital rape. The New York Times reported on how India recently ruled that "forced marital sex is not rape" (Vyawahare, 2014), thereby creating a conflicting definition of rape as compared to Norway. Definitions may vary depending on the individual's gender and relationship, with all of these different definitions possibly playing a part in this discussion.

As a result, there can be a difference in what "marriage" means, but it is usually tied to some legal rights or legislature. The part that influences this discussion is what rights husbands and wives have in relation to each other, which may be legal rights and/or informal rights. For example, an informal right in the US may be to know where your spouse is. There is no law about this, and some other places do not have the same informal right. A legal right may be having next-of-kin status with your spouse, and with next-of-kin status in the US, you could make emergency medical decisions for your spouse if they are unable to. Marriage rights do vary depending on what context you are in, as some cultures assume that husbands have an informal or legal right to have sex with their wife, with or without her consent. This would make the definition of marriage different in different contexts. This context may influence a person's opinion on what marriage is.

A definition of "gender" is also important to consider. Connell discusses how gender is often thought of as physical differences between men and women, which can be 
questioned (2013). Connell argues that women are not actually more dainty and less interested in sex than men, and that men are not more rational thinkers and more aggressive than women (2013). This information can be useful to this situation because it contradicts the stereotypes of men and women, as gender stereotypes may influence opinions just like culture does. Definitions of gender differ throughout the world. In Norway, jobs do not have a gender requirement, although some jobs do have a gender requirement in other countries. In Norway and the US, both men and women have the right to accept or decline sexual advances. In some countries, this right is based on your gender, and in some cases gender may also define gender roles and expectations. The many different definitions of gender may therefore influence this discussion.

I am fairly sure that our class has a handful of different definitions of marriage, rape and gender, and I assume that defining part of marriage as a husband's right to sleep with his wife has played a part in this topic. But when I asked people if they thought that a wife could rape her husband, the responses were similar. Some felt that a husband has a right to his wife, and that it is not possible for a woman to rape a man. But some others felt that it was not possible to have rape within a marriage, whereas others may feel that rape can take place in a marriage, but that men cannot be raped. And some students felt that rape could happen to either gender in a marriage. Furthermore, the numerous combinations of definitions may help shape people's opinions and ideas in this discussion.

\section{What does this mean for the profession of social work?}

This discussion may be important for social work as a profession. In a context in which marital rape is an issue that most social workers are aware of, this issue may challenge their opinion. Being challenged may help social workers better understand why this is their opinion and where it came from, and it can also help them see how social change is very dynamic. What may have already been changed in one context may only just be starting to change in another. This idea is important for international social work because these issues may occur frequently, and for social work in general because of how globalized the world is becoming. 
The definition of rape also brings up another issue mentioned at the crisis center. If the woman who has been raped by her husband does not think it is rape, do you tell her that it is? I imagine that I may struggle with this as a social worker at the crisis center. It is a difficult subject to discuss, which may make the woman feel worse, though in the end I do think that it would be better for the woman. If money was being stolen from me I would want to be told, even if it was my own darling child that I never suspected and did not believe you when you told me. If you tell me I have rights and help me understand my position, I would be grateful in the long run. Using the same logic, I imagine that this is better for the women at the crisis center. I know the examples are quite different, but I expect that if a woman does not consider her husband to be a rapist, she may also not know about her rights. Helping a woman understand her rights may be an important part of a social worker's role at the crisis center, and this could open other doors of empowerment for the service user.

Should this logic be applied the same way in a country that does not view marital rape as a crime? Ethical considerations and human rights issues would argue that it should be handled carefully depending on the situation. I imagine that a service user reporting marital rape to a social worker, in a country where this is not considered a crime, could have many different outcomes. The social worker's resources to help the service user would be limited by their context. The social worker's opinion would perhaps also be influenced by context, which may mean that the service user does not get any help. In a worst-case scenario, the service user may be reported for committing the crime of refusing to have sex with her husband. This shows how important the IFSW's policies and others, such as the Universal Declaration of Human Rights, are to both the social worker and service user. A social worker may use these policies to help support the service user and promote change, while the service user could also be involved in this changing of the power structures.

Discussions similar to this one may be a way to further social work as a profession. Discussing serious and recent issues is important in keeping the profession, methods, and theories of social work modern and up to date. These discussions are also important when developing social work as a profession. For example, if social work is a new field in a country, various guidelines and principles may need to be 
decided, and if social workers engage in serious discussions, they may be able to better understand the topic.

\section{A Better Understanding}

As future social workers, this discussion was beneficial for my classmates and me to have. Before now, I had not discussed this issue with anyone who had a significantly different viewpoint to my own. I was aware of the other opinions, but it is different to hear the opinion first hand. It has helped me understand where, how and why people have different opinions on this matter, and discussing this matter has also helped me discuss my feelings about this issue. After the incident took place, I was feeling somewhat lost. How could my classmates think that? They are not unaware or uneducated, so what is their reasoning? After discussing this issue with my classmates, I understood their point of view better and felt that they understood mine better as well. It was really encouraging to have this discussion without heated arguments, but instead with open ears. I have found that this positive experience will motivate me in the future to have similar discussions, as it has helped me learn more about how to approach and discuss sensitive issues.

This experience has also increased my skills in collaborating with a multicultural group, which will be very useful in the future. Both Norway and the US have people with different cultures as social workers and service users. I used to be very nervous when discussing issues of differences in culture, beliefs, gender and opinions, but practicing this has helped me become less worried and more confident. I learned about being in the majority instead of the minority. I experienced the "grass is greener on the other side effect". By this I mean that, while in the minority I thought it would be better to be in the majority, and vice versa. 


\section{References}

Connell, R. (2013). Gender. 2nd ed. Cambridge: Polity Press.

Fook, J. (2010). Social Work Critical Theory and Practice. London: SAGE Publications Ltd.

International Federation of Social Workers (2014a). Statement of Ethical Principals. [online] (updated: 3 March 2012). Available at: <http://ifsw.org/policies/statement-of-ethical-principles/> [Accessed 28 April 2014].

Lustig, M. W. \& Koester, J. (2010). Intercultural Competence: Interpersonal Communication across Cultures. 6th ed. Boston: Pearson Education Inc.

Lustig, M. W. \& Koester, J. (2010). Intercultural Competence: Interpersonal Communication across Cultures. 6th ed. Boston: Pearson Education Inc.

United Nations (1948). The Universal Declaration of Human Rights. [online] Available at: < http://www.un.org/en/documents/udhr/> [Accessed 12 May 2014].

Vyawahare, M. (2014). Indian Court Says Forced Marital Sex Is Not Rape. The New York Times Company, [online] 12 May. Available at: <http://www.nytimes.com/2014/05/13/world/asia/indian-court-says-forcedmarital-sex-is-not-rape.html> [Accessed 13 May 2014]. 